\title{
İklim Değişimi Senaryoları ve Tür Dağılım Modeline Göre Kızılcık (Cornus mas L.) Türünün Odun Dışı Orman Ürünleri Kapsamında Değerlendirilmesi
}

\author{
Ayhan $\mathrm{Akyol}^{1 *}$, Ömer Kamil Örücü \\ ${ }^{1}$ Isparta Uygulamalı Bilimler Üniversitesi, Orman Fakültesi, Orman Mühendisliği Bölümü, Isparta, Türkiye (ORCID: 0000-0001-6442-0256) \\ ${ }^{2}$ Süleyman Demirel Üniversitesi, Mimarlık Fakültesi, Peyzaj Mimarlığı Bölümü, Isparta, Türkiye (ORCID: 0000-0002-2162-7553)
}

(İlk Geliş Tarihi 3 Eylül 2019 ve Kabul Tarihi 27 Eylül 2019)

(DOI: 10.31590/ejosat.615019)

ATIF/REFERENCE: Akyol, A. \& Örücü, Ö. K. (2019). İklim Değişimi Senaryoları ve Tür Dağılım Modeline Göre Kızılcık (Cornus mas L.) Türünün Odun Dışı Orman Ürünleri Kapsamında Değerlendirilmesi. Avrupa Bilim ve Teknoloji Dergisi, (17), 224-233.

$\ddot{O} \mathbf{z}$

İklim değişimi bugün dünya üzerindeki tüm canlıları etkilemekte ve doğanın dengesini değiştirmektedir. Doğanın dengesinin bozulması, içindeki tüm canlı unsurların değişim ve dönüşümünü ifade ederken insan refahı, ekosistem hizmetleri ve biyoçeşitlilik bağlamında da ciddi kayıplar anlamına gelmektedir. Bu bağlamda son yıllarda odun dışı orman ürünleri ile ilgili yapılan sosyoekonomik çalışmaların yanı sıra ekolojik çalışmalarında arttığı görülmektedir. Bu kapsamda kızılcık (Cornus mas L.) odun dışı orman ürünleri kapsamında katma değeri oldukça yüksek bir tür olarak öne çıkmaktadır. Ancak, C. mas'ın habitatını şekillendiren önemli çevresel faktörler hakkında az şey bilinmektedir. Bu nedenle çalışmada, yüksek çözünürlüklü çevresel veriler kullanılarak $C$. mas'ın Türkiye'deki mevcut yayılış alanları ve iklim değişimine bağlı olarak geliştirilen senaryolara göre gelecek projeksiyonu MaxEnt 3.4.1 programı kullanılarak modellenmiştir. Modellemede CCSM4 (The Community Climate System Model) 2050 ve 2070 yll RCP (Representive Concentration Pathway) 4.5 ve RCP 8.5 iklim senaryosu kullanılarak oluşturulmuş 19 biyoklimatik değişken kullanılmıştır. Çalışma bulgularına göre, $C$. mas'ın günümüz tahmini potansiyel habitatı mevcut coğrafi dağılımı ile büyük ölçüde uyuşmaktadır. Jackknife testinin sonuçlarına göre C. mas'ın potansiyel dağılımında en yüksek kazancı olan çevresel değişken bio7 (yıllık sıcaklık oranı (Bio5-Bio6))'dır. İhmal edildiğinde kazancı en çok azaltan çevresel değişken ise bio15 (mevsimsel yağış miktarı (değişim katsayısı)) olmuştur. RCP 4.52050 ve 2070 projeksiyonları ile RCP8.5 2050 projeksiyonunda C. mas'ın yayılış alanının artmakta, RCP 8.52070 projeksiyonunda ise yayılış alanı azalmaktadır. C. mas gelecekte büyük bir habitat kaybına uğramamakta ancak coğrafi dağılışını Türkiye'nin kuzey ve kuzey batı bölgelerine doğru değiştirmekte ve buralardaki yayılışını genişletmektedir. Bu durum odun dışı orman ürünleri kapsamında değerlendirildiğinde ekonomik açıdan önem taşıyan, gıda güvenliğine katkı sağlayan ve kırsal kalkınma çalışmalarında kullanılan bir tür olarak C. mas'ın önemini daha da artırmaktadır. Bu nedenle iklim değişikliği ve türlerin etkileşimine yönelik daha kapsamlı çalışmalar yapılmalı ve bu etkileşimler ekonomik ve sosyal açılardan da değerlendirilmelidir.

Anahtar Kelimeler: İklim değişikliği, Tür dağılım modelleri, MaxEnt, Habitat uygunluğu, Cornus mas L.

\section{Investigation of Cornelian Cherry (Cornus mas L.) in the Scope of Non-Wood Forest Products According to Climate Change Scenarios and Species Distribution Model}

\begin{abstract}
Climate change is now affecting all living being on earth and changing the balance of nature. While disruption of the balance of nature means a change and transformation in all living elements in the environment, it also means severe losses in terms of human prosperity, ecosystem services and biodiversity. In this context, it is recently seen that, in addition to socio-economic studies on non-
\end{abstract}

\footnotetext{
* Sorumlu Yazar: Isparta Uygulamalı Bilimler Üniversitesi, Orman Fakültesi, Orman Mühendisliği Bölümü, Isparta, Türkiye, ORCID: 0000-00016442-0256, ayhanakyol@isparta.edu.tr
} 
wood forest products, ecological studies have also increased in numbers. Hence, the cornelian cherry (Cornus mas L.) is a prominent one with high added value especially as a non-wood forest product. However, little is known about the significant environmental factors that shape the habitat of $C$. mas L. Therefore, using high-resolution environmental data, the existing distribution areas of $C$. mas in Turkey and its future projections based on scenarios of climate change were modelled by using the MaxEnt 3.4.1 software. The modelling process utilized 19 bioclimatic variables that were formed by using the CCSM4 (The Community Climate System Model) 2050 and 2070 Representative Concentration Pathway (RCP4.5-8.5) climate scenarios. According to the findings of the study, the estimated potential habitat of $C$. mas for today is in a great agreement with its existing geographical distribution. According to the results of the Jackknife test, the environmental variable that provides the largest gain in the potential distribution of $C$. mas L. is bio7 (Temperature Annual Range (bio5-bio6)). The environmental variable that reduces the gain the most when it is neglected is bio15 (Precipitation Seasonality (Coefficient of Variation)). In the RCP4.5 2050 and 2070 projections and the RCP8.5 2050 projection, the distribution area of C. mas L. increases, while its distribution area decreases in the RCP8.5 2070 projection. C. mas L. does not experience a large habitat loss in the future, but it shifts its geographical distribution towards the northern and northwestern parts of Turkey. Considering this situation in terms of NWFPs, as a species with economic importance, contribution to food safety and usage in rural development practices, $C$. mas becomes even more significant. Therefore, more comprehensive studies should be carried out on climate change and interactions of species and these interactions should also be evaluated in the economic and social sense.

Keywords: Climate change, Species distribution models, MaxEnt, Habitat suitability, Cornus mas L.

\section{Giriş}

Türkiye bitki tür çeşitliliği açısından oldukça zengin bir ülke olup, doğal olarak yayılış gösteren, odun dışı orman ürünü (ODOÜ) niteliği taşıyan ve ticari öneme sahip olan birçok bitki türü bulunmaktadır. Özellikle kırsal alanlarda yaşayan ve bu bitkilerden direkt ve dolaylı olarak faydalanan insanların sayısı oldukça fazla olup bu türler kırsal kalkınma çalışmaları açısından da büyük önem taşımaktadır. Bu kapsamda Türkiye orman ekosistemlerinde doğal olarak yayılış gösteren kızılcık (Cornus mas L.) ekonomik açılardan önemli türlerden birisidir. C. mas Umbelliflorae takımının Cornaceae familyasından, kışın yapraklarını döken çalı veya 7-8 metreye kadar boylanabilen, gövde çapı 25-45 cm olan bir bitki türüdür (Baytop, 1984). Genelde bahçe ve tarla kenarlarında tek veya birkaç ağaç halinde ya da ormanlık alanlarda doğal olarak yetişmektedir (Güleryüz ve Pırlak, 1996). Yüksek besleyici değere sahip olması, farklı şekillerde kullanılabilmesi ve tıbbi özellikleri nedeniyle türe olan ilgi son yıllarda oldukça artırmıştır. Türkiye, Dünyada önemli kızılcık üreticileri arasında bulunmakta olup, son verilere göre 1511 dekar alanda 11000 tona yakın kızılcık üretimi yapılmaktadır (TÜİK, 2014; Güneş vd., 2016). Türün doğal olarak yayılış gösterdiği ormanlık alanlarda ise aşırı yararlanma ve plansız müdahaleler nedeniyle meyve verimleri düşmüş ve alanlar bozulmuş durumdadır (Akyol ve Tanas, 2019). Türü tehdit eden diğer bir unsur ise, sera gazı emisyonlarının yol açtı̆̆ı ve günümüzde küresel gündemin de başında yer alan küresel ısınma ve iklim değişikliği konularıdır.

Sera gazı emisyonlarının yol açtığı küresel ısınma ve iklim değişikliği Hükümetlerarası İklim Değişikliği Paneli (IPCC)'ne göre, küresel ortalama sıcaklık 1880-2012 yılları arasında $0.85{ }^{\circ} \mathrm{C}$ artmıştır (IPCC, 2014). C. mas katma değeri yüksek bir tür olmakla birlikte, türün gelecekte küresel ısınma ve iklim değişikliklerinden nasıl etkileneceği ve coğrafi dağılımının nasıl şekilleneceği konuları halen belirsizliğini korumaktadır. Bilindiği üzere iklim, türlerin dağılımında belirleyici bir rol oynamaktadır (Guisan ve Thuiller, 2005). Bu nedenle, türlerin ekolojik ihtiyaçlarını belirlemek ve potansiyel dağılım aralığını tahmin etmek için tür dağılım modelleri kullanılmaktadır (Franklin, 2013). Değişen çevresel süreçlere bağlı olarak, tür dağılımlarının anlaşılması türlerin koruma stratejilerinin tasarlanması ve gelecekte de sürdürülebilir bir şekilde kullanılmalarının sağlanması açısından önemlidir (Guisan ve Thuiller, 2005; Falcucci vd., 2007). En yaygın olarak kullanılan tür dağılım modellerinden birisi olan Maksimum Entropi Modeli, bir türün habitatının uygunluğunu farklı çevresel değişkenlerin nasıl etkilediğini açıklamaya çalışan bir modeldir.

Bu olgulardan hareketle çalışmanın amaçları, C. mas'ın potansiyel dağılımını etkileyen önemli çevresel faktörleri belirlemek, $C$. mas'ın farklı iklim senaryolarına bağlı olarak gelecekteki potansiyel dağılımını tahmin etmek ve bu tahminlere dayanarak $C$. mas'ın özellikle ODOÜ kapsamında kullanımı, korunması ve geliştirilmesi ile ilgili planlamacılara referans veriler sunmaktır.

\section{Materyal ve Metot}

\subsection{Materyal}

Çalışma materyali odun dişı orman ürünleri kapsamında orman köylerine ve köylülerine alternatif gelir kaynağı olan, gıda güvenliklerine katkı sağlayan, kırsal kalkınma amaçlı kullanılabilen, meyveleri tıbbi açıdan önem taşıyan ve ticari olarak oldukça önemli bir tür olan Cornus mas L.'dir.

\subsection{Metot}

C. mas'ın küresel iklim değişikliği karşısında gelecekteki yayılış alanlarının belirlenmesi amacıyla çalışmada yöntem olarak tür dağılım modeli kullanılmıştır. Bu kapsamda MaxEnt 3.4.1 versiyonu (Phillips vd., 2004; Elith vd., 2011) ile küresel iklim değişikliğine bağlı olarak C. mas'ın dağılım alanları için 2050 (2041-2060 ortalaması) ve 2070 (2061-2080 ortalaması) yılları periyodu maksimum entropi modelleri üretilmiştir.

Çalışmada mevcut durum ve öngörülen gelecek için biyoklimatik değişkenler WorldClim veri tabanından elde edilmiştir (Hijmans vd., 2005; WorldClim, 2019). Tablo 1'de IPCC 2014 raporu temel alınarak hazırlanmış CCSM4 (The Community Climate System Model) 2050 ve 2070 y1l RCP (Representive Concentration Pathway) 4.5 ve RCP 8.5 iklim senaryosu kullanılarak 
oluşturulmuş 19 biyoklimatik değişken görülmektedir. RCP'ler iklim modellemelerinde yakın gelecekteki sera gazı salınımı yoğunluklarına bağlı olarak mümkün olduğu düşünülen iklim senaryolarını tanımlamak için kullanılmaktadır (Moss vd., 2008). CCSM, dünyanın iklim sistemini simüle etmek için kullanılan bir iklim modelidir. Dünyanın atmosferini, okyanus, kara yüzeyini ve deniz buzullarını eş zamanlı olarak simüle eden dört ayrı modelden oluşan CCSM, araştırmacıların dünyanın geçmiş, şimdiki ve gelecekteki iklim durumları hakkında temel araştırmalar yapmalarına izin vermektedir (CESM, 2019).

Tablo 1. Biyoklimatik Değişkenler

\begin{tabular}{|c|c|}
\hline Kodlar & Tanımlar \\
\hline bio_01 & Yillık ortalama sicaklık \\
\hline bio_02 & Sıcaklık değişim aralığı (aylık ortalama (max sıcaklık-min sıcaklık)) \\
\hline bio_03 & İzotermalite (Bio2/Bio7) $(* 100)$ \\
\hline bio_04 & Mevsimsel sicaklık (standard sapma *100) \\
\hline bio_05 & En sıcak ayın maksimum sıcaklığı \\
\hline bio_06 & En soğuk ayın minimum sıcaklığı \\
\hline bio_07 & Y1llık sicaklık oranı (Bio5-Bio6) \\
\hline bio_08 & En nemli çeyreğin ortalama sıcaklığı \\
\hline bio_09 & En kurak çeyreğin ortalama sıcaklığ \\
\hline bio_10 & En sıcak çeyreğin ortalama sıcaklığı \\
\hline bio_11 & En soğuk çeyreğin ortalama sıcaklığ1 \\
\hline bio_12 & Yıllık yağış \\
\hline bio_13 & En nemli aydaki yağış miktarı \\
\hline bio_14 & En kurak aydaki yağış miktarı \\
\hline bio_15 & Mevsimsel yağış miktarı (Değişim katsayısı) \\
\hline bio_16 & En nemli çeyreğin yağış miktarı \\
\hline bio_17 & En kurak çeyreğin yağış miktarı \\
\hline bio_18 & En sıcak çeyreğin yağgş miktarı \\
\hline bio_19 & En soğuk çeyreğin yağ1ş miktarı \\
\hline
\end{tabular}

Çalışma için tür varlığı verisi olarak kullanmak üzere, Türkiye'de C. mas'ın yayılış gösterdiği 28 noktadan 2019 yılında alınan kayıtlar kullanılmıştır (Tablo 2; Şekil 1) (Davis, 1982; Davis vd., 1988; GBIF, 2019). Çalışma kapsamında ayrıca MaxEnt modelleme programında çevresel değişkenlerin etkilerini ölçmeye sağlayan Jackknife seçeneği kullanılmıştır. Bu seçenek her bir bağımsız değişkenin modelin oluşturulmasındaki önem derecelerini belirlemeye olanak tanımaktadır. Potansiyel dağılım haritaları oluşturulurken 0 ve 1 değerleri kullanılmış olup, buna göre 1 türün bulunabileceği en uygun alanı gösterirken, 0 bulunma olasılığ1 olmadığı anlamına gelmektedir. 


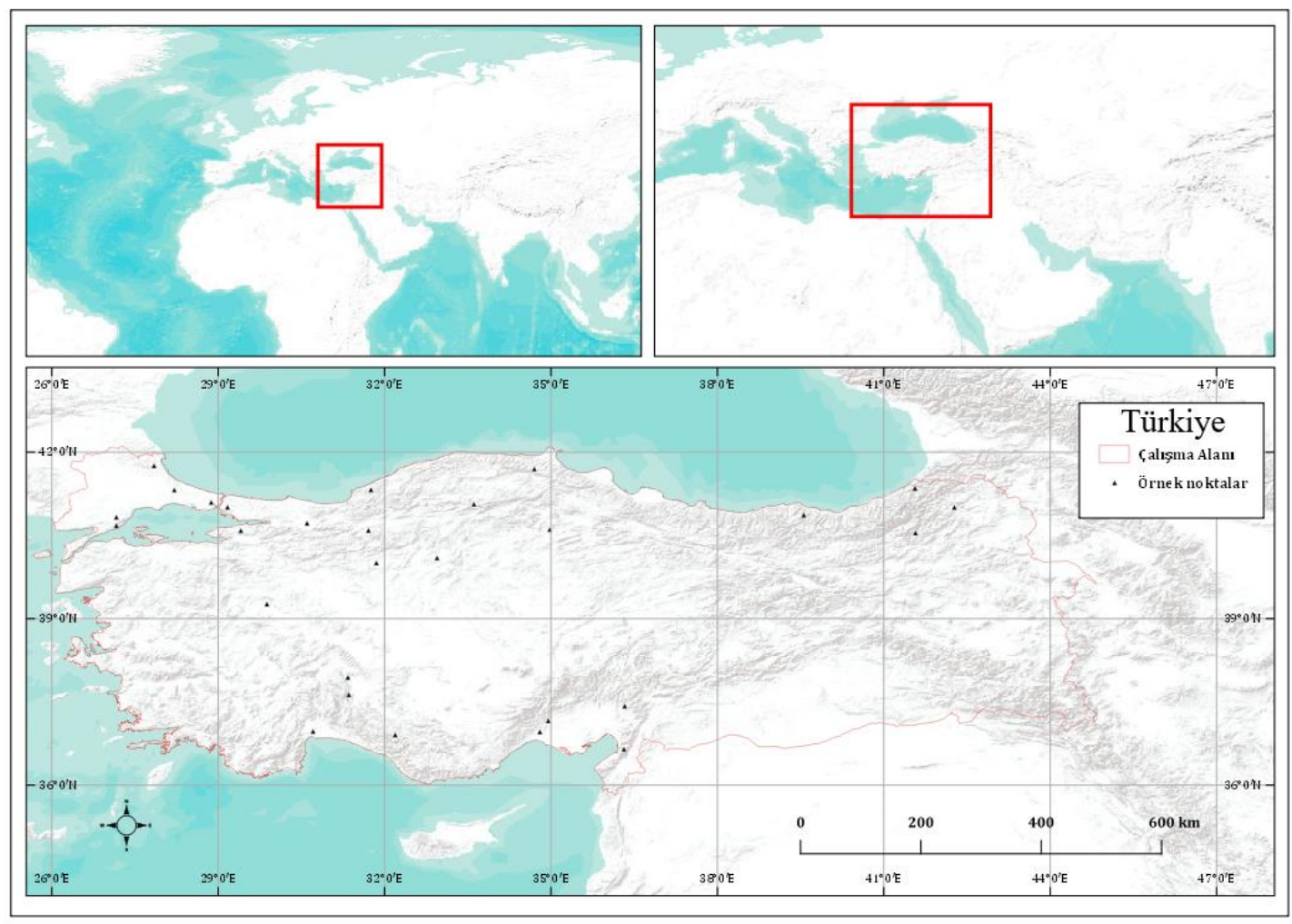

Şekil 1. Çalı̧̧ma Alanı ve Örnek Noktalar

Tablo 2. Varlık Verilerinin Coğrafi Koordinatları ile Öznitelik Bilgileri

\begin{tabular}{|c|c|c|c|c|c|c|}
\hline Örnek & İl/İlçe & $\mathbf{X}$ & $\mathbf{Y}$ & $\begin{array}{c}\text { Sicaklık } \\
\left(\text { Ort) }\left({ }^{\circ} \mathrm{C}\right)\right.\end{array}$ & $\begin{array}{c}\text { Yıllık Yağış } \\
\text { (mm) }\end{array}$ & $\begin{array}{c}\text { Rüzgar } \\
\text { (Ort) }(\mathrm{m} / \mathrm{sn})\end{array}$ \\
\hline 1 & Adana-Karaisalı & 34.95059 & 37.16571 & 17.99 & 768 & 1.93 \\
\hline 2 & Ankara-Beypazarı & 31.85237 & 40.00946 & 11.39 & 399 & 2.10 \\
\hline 3 & Ankara-Çubuk & 32.94612 & 40.09875 & 11.09 & 423 & 2.08 \\
\hline 4 & Antalya-Merkez & 30.70952 & 36.97375 & 18.30 & 726 & 2.22 \\
\hline 5 & Antalya-Gündoğmuş & 32.19166 & 36.91125 & 5.47 & 696 & 2.68 \\
\hline 6 & Artvin-Borçka & 41.56219 & 41.35321 & 8.53 & 1182 & 2.35 \\
\hline 7 & Artvin-Ardanuç & 42.27202 & 41.00946 & 1.58 & 832 & 2.33 \\
\hline 8 & Bolu-Merkez & 31.70952 & 40.59428 & 6.58 & 591 & 2.73 \\
\hline 9 & Çorum-Merkez & 34.97737 & 40.61214 & 9.98 & 488 & 2.02 \\
\hline 10 & Erzurum-Uzundere & 41.57112 & 40.54964 & 10.06 & 513 & 1.59 \\
\hline 11 & Hatay-Dörtyol & 36.31666 & 36.65232 & 13.10 & 879 & 2.78 \\
\hline 12 & Isparta-Aksu & 31.35684 & 37.63446 & 9.92 & 640 & 2.08 \\
\hline 13 & Isparta-Şarkikaraağaç & 31.33898 & 37.94696 & 11.33 & 585 & 2.08 \\
\hline 14 & İstanbul-Çatalca & 28.20952 & 41.32419 & 12.78 & 641 & 2.89 \\
\hline 15 & İstanbul-Sultangazi & 28.87469 & 41.10098 & 13.86 & 726 & 2.83 \\
\hline 16 & İstanbul-Ümraniye & 29.16934 & 41.01169 & 13.98 & 757 & 2.63 \\
\hline 17 & K. Maraş-Andırın & 36.33005 & 37.4291 & 17.50 & 776 & 1.81 \\
\hline 18 & Kastamonu-Araç & 33.6113 & 41.0675 & 6.44 & 576 & 2.38 \\
\hline 19 & Kırklareli-Demirköy & 27.84344 & 41.76169 & 11.87 & 633 & 3.23 \\
\hline 20 & Kütahya-Aslanapa & 29.87916 & 39.26839 & 10.13 & 597 & 2.28 \\
\hline 21 & Mersin-Tarsus & 34.7988 & 36.96482 & 17.53 & 757 & 2.28 \\
\hline 22 & Sakarya-Akyazı & 30.60237 & 40.72375 & 14.00 & 788 & 1.64 \\
\hline 23 & Sinop-Ayancık & 34.70059 & 41.70143 & 6.98 & 672 & 2.96 \\
\hline 24 & Tekirdağ-Şarköy & 27.16487 & 40.68134 & 12.92 & 705 & 3.44 \\
\hline 25 & Tekirdağ-Malkara & 27.16487 & 40.83312 & 13.65 & 679 & 2.78 \\
\hline 26 & Trabzon-Akçaabat & 39.55773 & 40.87107 & 8.84 & 726 & 2.29 \\
\hline 27 & Yalova-Altınova & 29.40818 & 40.59205 & 12.86 & 668 & 2.52 \\
\hline 28 & Zonguldak-Merkez & 31.75416 & 41.32643 & 11.53 & 827 & 2.58 \\
\hline
\end{tabular}




\section{Araştırma Sonuçları ve Tartışma}

C. mas'ın iklim değişimine bağlı olarak gelecekteki yayılış alanlarının belirlendiği bu çalışmada MaxEnt modellerinin performansı ROC (Receiver Operating Characteristic) analizleri ile test edilebilmektedir. Sonuçta elde edilen AUC (Area Under the ROC Curve) değeri doğru ayarlanmış bir modelde rastgele seçilen grid hücresinin varlığının tahmini olasılığı olarak yorumlanabilir. AUC tüm olası eşiklerle modelin başarısını tanımlamaktadır. Eğer bu değer AUC $>0.5$ ise modelin rastgele bir tahminden daha iyi performans gösterdiğini göstermektedir (Phillips, 2010). AUC değeri l'e ne kadar yakınsa ayrım o kadar iyi, model hassas ve tanımlayıcıdır (Oliveira vd., 2010). Çalışma kapsamında elde edilen ROC eğrisindeki 0.861 AUC değeri modelin hassaslığını kanıtlamaktadır (Şekil 2). (AUC $\geq 0.9=$ çok iyi, $0.9>\mathrm{AUC} \geq 0.8=$ iyi ve $\mathrm{AUC}<0.8=$ zayıf) (Gassó vd., 2012). Bu sonuçlar, model performansının iyi olduğunu yani modelin yüksek bir tahmin gücü olduğunu göstermektedir.

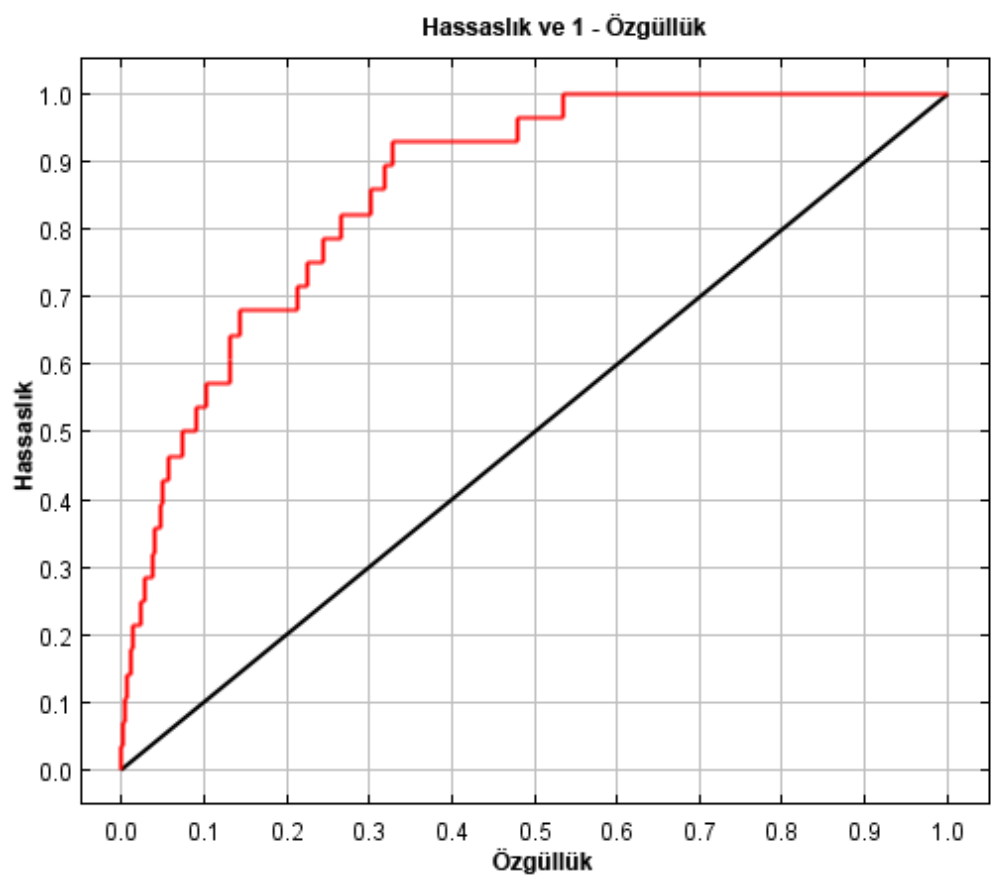

Eğitim verisi (AUC $=\mathbf{0 . 8 6 1 )}$ " Rastgele tahmin (AUC=0.5) .

Şekil 2. Ĕgitim Verisi AUC Değeri

Buna göre, C. mas'ın mevcuttaki yayılış alanları Şekil 3'te, iklim değişikliğine bağlı olarak gelecekteki yayılış alanları 2050 ve 2070 yılları periyodunda RCP 4.5'e göre Şekil 4 ve RCP 8.5'e göre Şekil 5'de gösterilmektedir. Modellerde uygun olmayan alanlar mavi, uygun alanlar sarı çok uygun alanlar ise kırmızı renkle sembolize edilmiştir. Siyah üçgenler, modelin oluşturulması için kullanılan varlık verilerini göstermektedir.

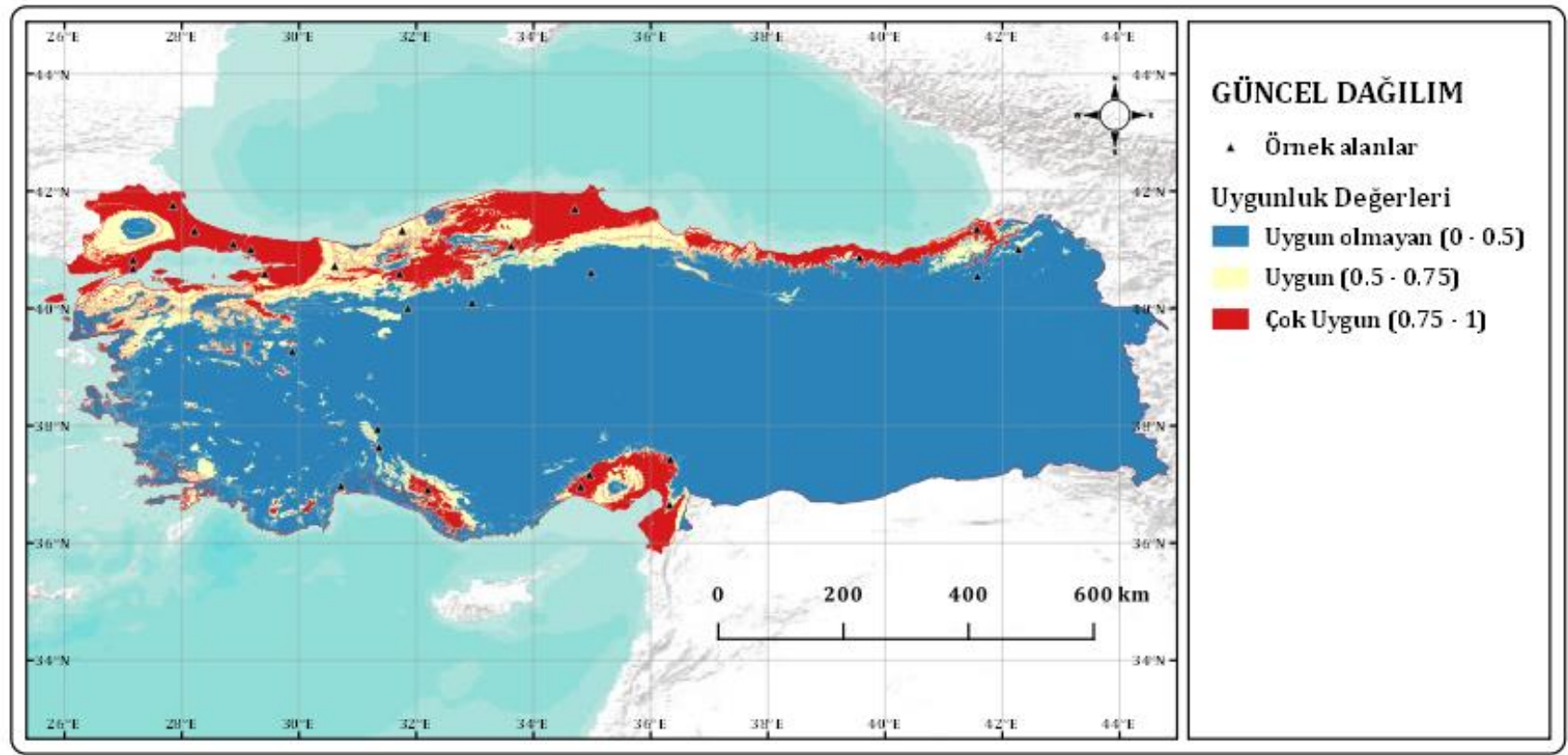

Şekil 3. C. mas L. ’nin MaxEnt Tür Dağıllım Modeline Göre Potansiyel Yayıllı̧ Alanı 


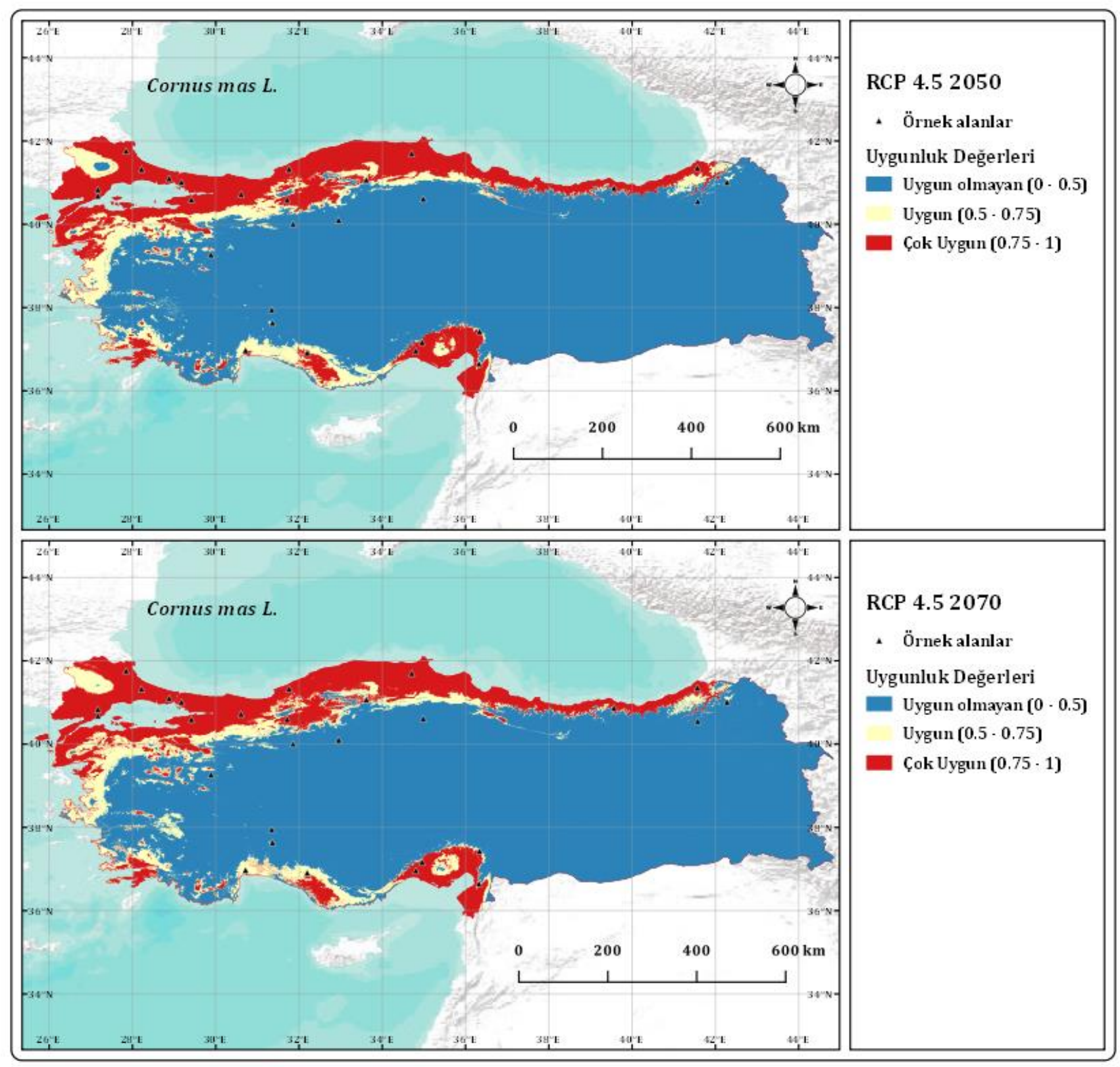

Şekil 4. RCP 4.5'e Göre 2050-2070 Projeksiyonlarında Yayllı̧̧ Alanları Modeli 


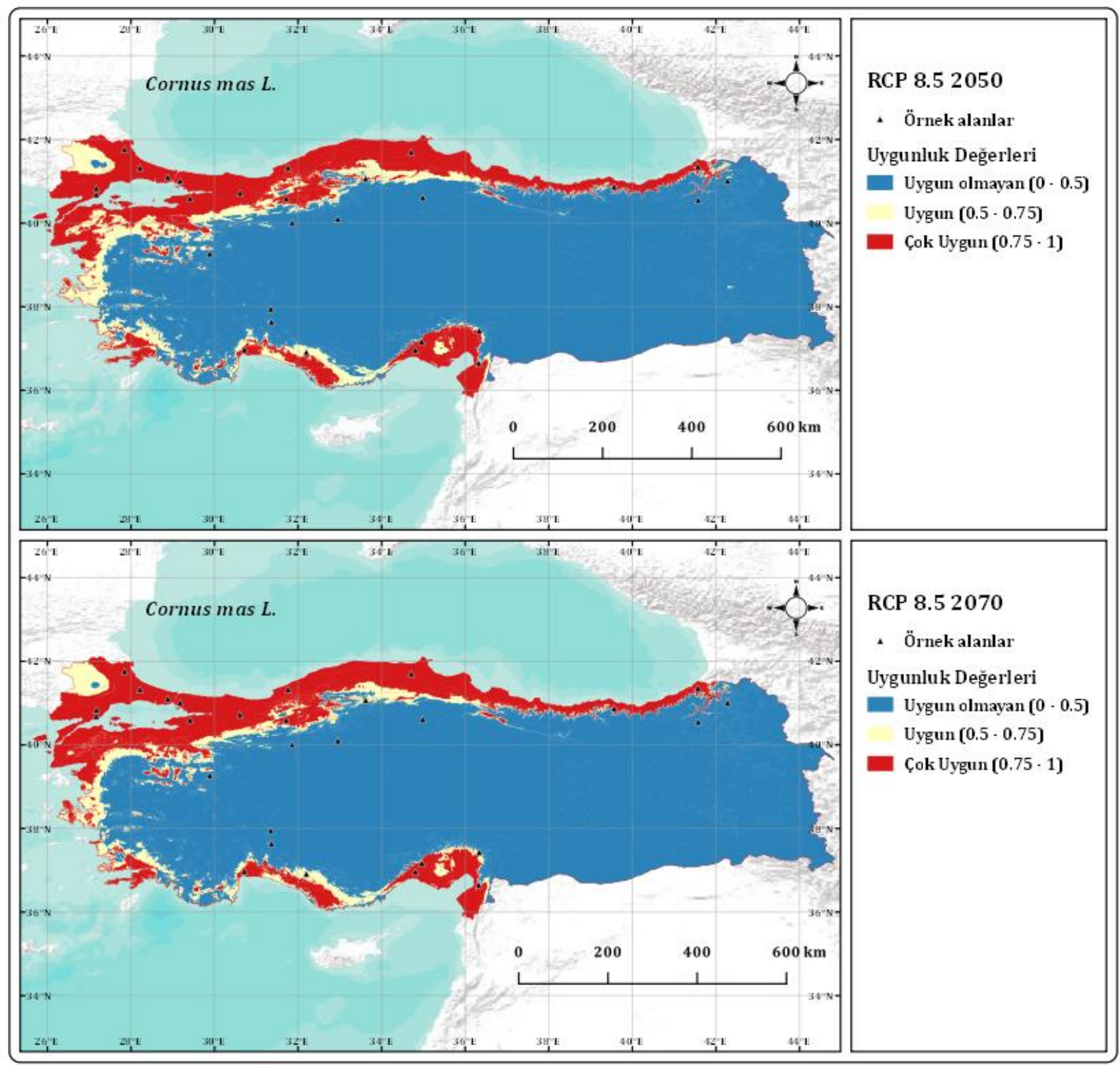

Şekil 5. RCP 8.5'e Göre 2050-2070 Projeksiyonlarında Yayllış Alanları Modeli

MaxEnt modelinde bir türün alanda bulunma oranı 0-1 arasında bir değer ile belirlenmektedir. Değerler 1'e yaklaştıkça türün potansiyel olarak o alanda bulunma oranı artmaktadır. Bu nedenle çalışmada, C. mas'ın ticari değerinin yüksek olması ve kültüre alınarak üretime konu olmasından dolayı türe ait mevcut ve potansiyel dağılımın belirlenmesinde bulunma oranı 0.5 'in üzerinde olan alanlar değerlendirmeye alınmıştır. Buna göre, C. mas'ın RCP 4.5 ve RCP 8.5'a göre 2050-2070 projeksiyonlarında türün yayılış alanları modeli incelendiğinde (Tablo 3), yayılış alanı çok uygun habitat alanları (0.75-1) günümüz iklim koşullarında $96749 \mathrm{~km}^{2}$ iken, RCP 4.52050 projeksiyonunda $139409 \mathrm{~km}^{2}$, RCP 4.52070 projeksiyonunda $136321 \mathrm{~km}^{2}$, RCP 8.52050 projeksiyonunda $141523 \mathrm{~km}^{2}$ ve RCP 8.52070 projeksiyonunda $142404 \mathrm{~km}^{2}$ olduğu görülmektedir. Yani $C$. mas'ın gelecekteki çok uygun $(0.75-1)$ yayılış alanları artmaktadır.

Tablo 3. C.mas L. 'nin Güncel ve Gelecek Projeksiyonlarına Göre Yayılış Alanları $\left(\mathrm{km}^{2}\right)$

\begin{tabular}{c|r|r|r|r|r|r|r|r|r}
\hline Uygunluk Durumu & Güncel & RCP4.5 2050 & Fark & RCP4.5 2070 & Fark & RCP8.5 2050 & Fark & RCP8.5 2070 & Fark \\
\hline Uygun Olmayan (0-0.5) & 568138 & 555807 & 12331 & 552805 & 15334 & 558319 & 9820 & 569662 & -1524 \\
\hline Uygun (0.5-0.75) & 114633 & 84305 & 30329 & 90395 & 24239 & 79679 & 34954 & 67454 & 47179 \\
\hline Çok Uygun (0.75-1) & 96749 & 139409 & -42660 & 136321 & -39572 & 141523 & -44774 & 142404 & -45655 \\
\hline Toplam & 779521 & 779521 & & 779521 & & 779521 & & 779521 & \\
\hline
\end{tabular}


Ancak uygun (0.5-0.75) habitat alanları günümüz iklim koşullarında $114633 \mathrm{~km}^{2}$ iken, RCP 4.52050 projeksiyonunda 84305 $\mathrm{km}^{2}$, RCP 4.52070 projeksiyonunda $90395 \mathrm{~km}^{2}$, RCP 8.52050 projeksiyonunda $79679 \mathrm{~km}^{2}$ ve RCP 8.52070 projeksiyonunda 67454 $\mathrm{km}^{2}$ olduğu görülmektedir. Yani $C$. mas'ın gelecekteki uygun potansiyel yayılış alanları azalmaktadır. Elde edilen bu bulgular türün gelecekteki potansiyel yayılış alanlarının niteliğinin değişeceğini göstermektedir. Özellikle habitatlar uygun (05-0.75) alanlardan çok uygun (0.75-1) alanlara doğru değişmektedir. Bu nedenle gelecekte özellikle ODOÜ üretimine ilişsin planlamalarda bu duruma dikkat edilmelidir. Yine elde edilen bu bulgular, önümüzdeki 50 yıl içerisinde özellikle kırsal kalkınma çalışmaları için alan seçiminde modelde belirlenen potansiyel dağılım alanlarının dikkate alınmasını gerekli kılmaktadır.

Şekil 3, 4 ve 5 yani güncel durum ve gelecek projeksiyonları bir bütün olarak incelendiğinde ise $C$. mas'ın habitat kayıp ve kazançları bağlamında büyük bir değişim yaşamayacağını göstermektedir. Ancak, modele göre Türkiye'nin güney bölgelerinde habitat kayıpları yaşanırken kuzey ve kuzey batı bölgelerinde habitat artışı yaşanacaktır. Bu bulgulara göre C. mas yayılışını daha kuzeye doğru değiştirmekte ve buradaki yayılışını genişletmektedir. İklim değişikliklerinin etkilerine yönelik yapılan diğer bazı çalışmalarda bazı bitki ve böcek türlerinin coğrafi yayılışlarının artacağı sonuçlarına ulaşılmıştır (West vd., 2015; Sarıkaya vd., 2018. Wei vd., 2018). Günümüzde istilacı olmayan bu türlerin oluşabilecek habitat kayıpları ve iklimsel değişikliklere bağlı olarak istilacı türler haline gelebilecekleri de öngörülmektedir. Ancak, özellikle yayılış alanı sınırlı türlerin iklim değişikliklerinden olumsuz etkilenecekleri bildirilmektedir (Moiseev ve Shiyatov, 2003; Mert vd., 2016; Dülgeroğlu ve Aksoy, 2018). Bu durumunun ise ekosistem hizmetleri kapsamında çeşitli hizmetlerde kayıplara ve insan refahında azalmalara yol açacağı çeşitli çalışmalarla ifade edilmektedir (Arslan, 2019). Bu nedenle gelecek yıllar için uygun önlemlerinin alınması ve kırsal kalkınma çalışmalarında bu durumun dikkate alınarak planlamaların yapılması türün yarattığı yüksek katma değerin devamlılığı açısından önem taşımaktadır.

Jackknife MaxEnt modelleme programında çevresel değişkenlerin etkilerini ölçmeye sağlayan bir seçenektir. Bu seçenek her bir bağımsız değişkenin modelin oluşturulmasındaki önem derecelerini belirlemeye olanak tanımaktadır. Buna göre C. mas için modelde jackknife seçeneği işaretlenerek elde edilen kazanım tablosu Şekil 6'da verilmiştir. Jackknife testinin sonuçlarına göre izolasyonda kullanıldığında en yüksek kazancı olan çevresel değişken bio7 (yıllık sıcaklık oranı (Bio5-Bio6)'dır. Bu nedenle kendi başına en yararlı bilgiye sahip görünmektedir. Diğer bir değişken ise bio2 (sıcaklık değişim aralı̆̆ (aylık ortalama (max sıcaklık-min sıcaklık))'dir. İhmal edildiğinde kazancı en çok azaltan çevresel değişken ise bio15 (mevsimsel yağı̧ miktarı (değişim katsayısı)) olup, bu nedenle diğer değişkenlerde bulunmayan en fazla bilgiye sahip görünmektedir. Bu bulgular türün dağılımını etkileyen en önemli çevresel değişkenlerin sıcaklık ile ilgili değişkenler olduğunu göstermektedir.

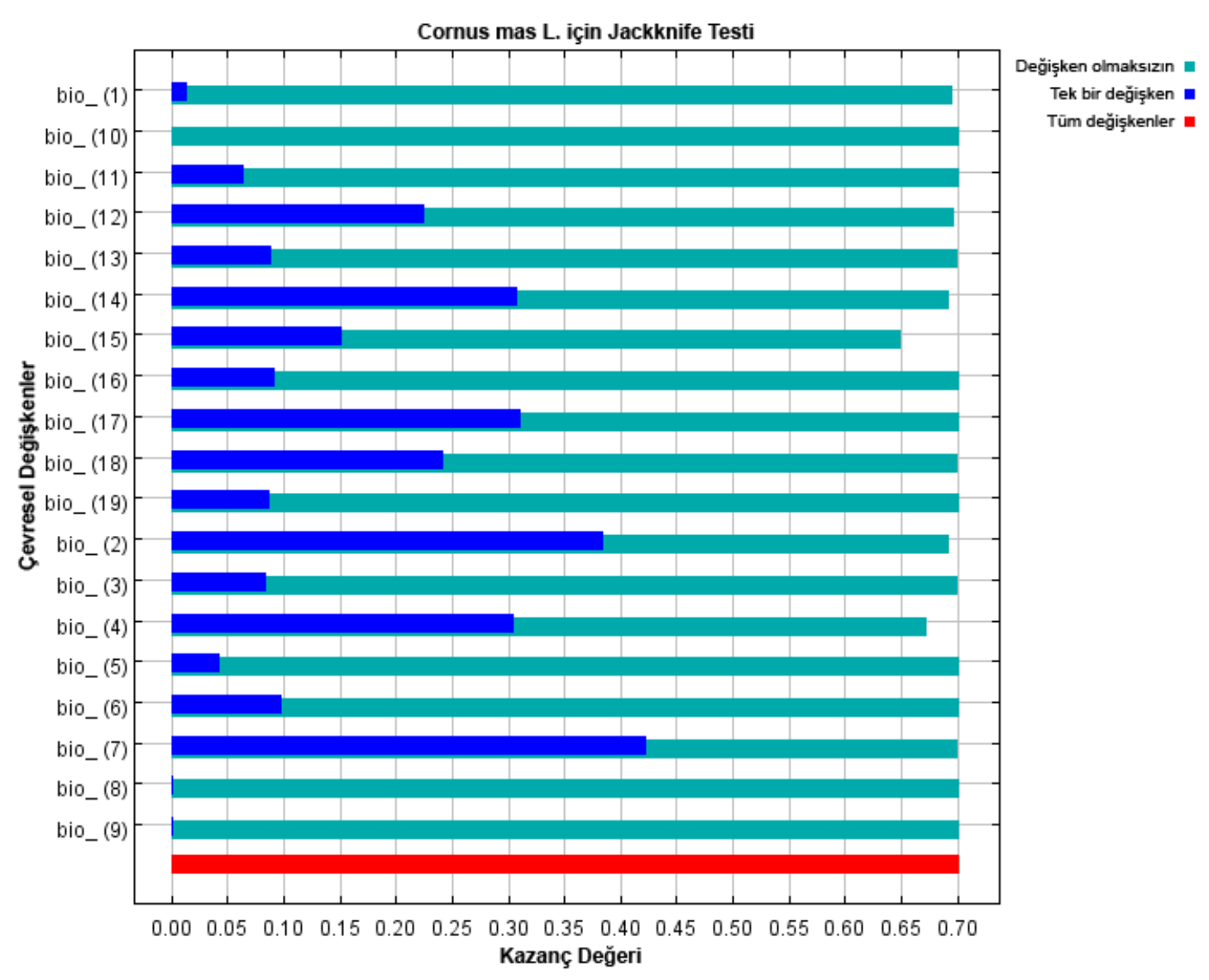

Şekil 6. Jackknife Çevresel Değişkenlerin Etki Dereceleri 


\section{Sonuç}

C. mas L. ekonomik değeri yüksek bir tür olup, ODOÜ kapsamında ve kırsal kalkınma amaçlı çalışmalarda tercih edilmektedir. Türün gelecekte kendisinden beklenen ekolojik, ekonomik ve sosyal faydaları sürdürebilmesi için orman ekosistemi özelliklerine bağlı olarak coğrafi dağılımı üzere daha fazla çalışmaya ihtiyaç vardır. Elde edilen sonuçlar, gelecekte Türkiye'de C. mas'ın diğer pek çok türe kıyasla habitat kaybına uğramayacağını ancak coğrafi dağılışını Türkiye'nin kuzey bölgelerine doğru değiştireceğini ve kuzeydeki yayılışını genişleteceğini göstermektedir. Bu durum ODOÜ kapsamında değerlendirildiğinde ekonomik açıdan önem taşıyan, gıda güvenliğine katkı sağlayan ve kırsal kalkınma çalışmalarında kullanılan bir tür olarak C. mas'ın önemini daha da artırmaktadır. İklim projeksiyonları gelecekte özellikle sınırlı yayılışa sahip birçok türün habitat kaybına uğrayacağını ve hatta yok olacağını öngörmektedir. Bu durumda C. mas vb. gibi yüksek katma değerli türlerin ekonomik amaçlarla daha çok tercih edileceği ve doğal yayılış alanlarında daha çok kullanım baskısına maruz kalacakları düşünülmektedir.

C. mas'ın yayılışının gelecekte Türkiye'nin kuzey bölgelerinde genişletmesi o bölgelerde yaşayanların gelir ve besin elde etmeleri açısından olumlu bir durumdur. Ancak özellikle iklim değişiminden önemli derecede ve olumsuz etkileneceği düşünülen Akdeniz bölgesi ve bölgede yaşayanlar için ise olumsuz bir durumdur. Bu olumsuzlukların başında iklim değişimine adapte olamayan ve sınırlı yayılışa sahip olan bitki türlerinin neden olacağı biyolojik çeşitlilik kayıpları yer almaktadır (Khanum vd., 2013; IPCC, 2014). Diğer olumsuzluklar ise ODOÜ kapsamında sağlanan gelirlerin ve gıda güvenliğine katkısının azalması şeklindedir. Ancak, iklim değişikliklerinin sadece bu olumsuzluklarla sonuçlanmadığı, ekosistemin birçok değişkenini etkilediği, farklı türlerin biyolojileri ve ekolojilerini değiştirdiği çeşitli araştırmalarla ortaya konulmaktadır. Ancak bu değişime rağmen farklı toplumlarda halen iklim değişikliği konusunun yeterince önemsenmediği ve iklim değişikliğgi ile ilgili bilgi ve bilinç düzeyinin artırılması gerektiği yapılan çalışmalarla ortaya konulmaktadır (Arbuckle vd., 2013; Mase vd., 2017; Korkmaz, 2018). Bu durum ise, özellikle orman ekosistemleri, korunan alanlar vb. diğer biyolojik çeşitliliğin yüksek olduğu ekosistemlerdeki planlamalara iklim değişikliği konusunun bütünleştirilerek, iklim değişikliği ve türlerin etkileşimine yönelik daha kapsamlı çalışmaların yapılmasını gerekli kılmaktadır. Ayrıca, iklim değişikliği ile ilgili yapılacak çalışmaların sadece ekolojik çalışmalarla sınırlandırılmaması ve bu çalışmalara toplumun iklim değiş̧ikliğine uyumu ile ilgili çalışmaların eklenmesi de önemlidir. Böylece, başta biyolojik çeşitliliğin korunması olmak üzere, çeşitli türlerden sağlanan ekolojik, ekonomik ve sosyal faydaların korunması ve sürdürülmesine devam edilebilecektir.

\section{Kaynakça}

Akyol, A. \& Tanas, E.K. (2019). Rehabilitasyon eylem planları çerçevesinde kızılcık (Cornus mas L.) rehabilitasyon çalışmalarının sosyo-ekonomik katkılarının irdelenmesi: Dursunbey Orman İşletme Müdürlüğü örneği. Turkish Journal of Forestry, 20(2): 101109.

Arbuckle, J.G., Morton, L.W. \& Hobbs, J. (2013). Farmer beliefs and concerns about climate change and attitudes toward adaptation and mitigation: Evidence from Iowa. Climatic Change, 118(3-4): 551-563.

Arslan, E.S. (2019). İklim değişimi senaryoları ve tür dağılım modeline göre kentsel yol ağaçlarının ekosistem hizmetleri bağlamında değerlendirilmesi: Robinia pseudoacacia L. örneği. Turkish Journal of Forestry, 20(2): 142-148.

Baytop, T. (1984). Türkiye'de Bitkiler ile Tedavi. İstanbul Üniversitesi Basımevi, Yayın No: 3255, İstanbul.

CESM, (2019). Community Earth System Model. http://www.cesm.ucar.edu/models/ccsm4.0/, Erişim Tarihi: 25.04.2019.

Davis, P.H., (1982). Flora of Turkey and the Aegean Islands. Vol. :I-IX, Edinburgh University Press, London.

Davis, P.H., Tan, K. \& Mill, R. (1988). Flora of Turkey and tha Aegean Islands. Vol. :X (supplement), Edinburgh University Press, London.

Dülgeroğlu, C. \& Aksoy, A. (2018). Predicting impacts of climate change on geographic distribution of Origanum minutiflorum Schwarz \& P.H. Davis using maximum entropy algorithm. Erzincan University Journal of Science and Technology, 11(2):182190.

Elith, J., Phillips, S.J., Hastie, T., Dudík, M., Chee, Y.E. \& Yates, C.J. (2011). A statistical explanation of MaxEnt for ecologists. Diversity and Distributions, 17 (1): 43-57.

Falcucci, A., Maiorano, L. \& Boitani, L. (2007). Changes in land-use/land-cover patterns in Italy and their implications for biodiversity conservation. Landscape ecology, 22(4): 617-631.

Franklin, J. (2013). Species distribution models in conservation biogeography: developments and challenges. Diversity and Distributions, 19(10): 1217-1223.

Gassó, N., Thuiller, W., Pino, J. \& Vilà, M. (2012). Potential distribution range of invasive plant species in Spain. NeoBiota, 12: $25-$ 40.

GBIF, (2019). Global Biodiversity Information Facility. www.gbif.org, Erişim tarihi: 14.02.2019.

Guisan, A. \& Thuiller, W. (2005). Predicting species distribution: offering more than simple habitat models. Ecology letters, 8(9): 993-1009.

Güleryüz, M. \& Pırlak, L. (1996).Türkiye'de Kızılcık (Cornus mas L.) Yetiştiriciliği. Derim, 13(3): 129-136.

Güneş, N.T., Özüpek, Ö. \& Bakoğlu, N. (2016). Amasya'da doğal olarak yetişen kızılcık (Cornus mas L.) meyvelerinin raf ömrü sürecinde bazı fizikokimyasal özelliklerindeki değişimler. Bahçe, Yalova Atatürk Bahçe Kültürleri Merkez Araştırma Enstitüsü Dergisi, 45(1): 680-684.

Hijmans, R.J., Cameron, S.E., Parra, J.L., Jones, P.G. \& Jarvis, A. (2005). Very high resolution interpolated climate surfaces for global land areas. International Journal of Climatology, 25: 1965-1978.

IPCC, (2014). Impacts, Adaptation and Vulnerability: Summary for Policymakers. Cambridge University Press, Cambridge, United Kingdom and New York. 
Korkmaz, M. (2018). Public awareness and perceptions of climate change: Differences in concern about climate change in the West Mediterranean Region of Turkey. Applied Ecology and Environmental Research, 16(4):4039-4050.

Mase, A.S., Gramig, B.M. \& Prokopy, L.S. (2017). Climate change beliefs, risk perceptions, and adaptation behavior among Midwestern US crop farmers. Climate Risk Management, 15: 8-17.

Mert, A., Özkan, K., Şentürk, Ö. \& Negiz, M.G. (2016). Changing the potential distribution of Turkey Oak (Quercus cerris L.) under climate change in Turkey. Polish Journal of Environmental Studies, 25(4): 1633-1638.

Moiseev, P.A. \& Shiyatov, S.G. (2003). The use of old landscape photographs for studying vegetation dynamics at the tree line ecotone in the Ural Highlands, Russia. In: Nagy, L. (Ed.), Alpine Biodiversity in Europe. Springer-Verlag, Berlin.

Moss, R.H., Babiker, M., Brinkman, S., Calvo, E., Carter, T., Edmonds, J.A. \& Zurek, M. (2008). Towards New Scenarios for Analysis of Emissions, Climate Change, Impacts, and Response Strategies. United States, IPCC Expert Meeting Report. Intergovernmental Panel on Climate Change, 34 pp. Geneva, Switzerland.

Oliveira, M.D., Hamilton, S.K., Calheiros, D.F., Jacobi, C.M. \& Latini, R.O. (2010). Modeling the potential distribution of the invasive golden mussel Limnoperna fortunei in the Upper Paraguay River system using limnological variables. Brazilian Journal of Biology, 70(3):831-840.

Phillips, S.J. (2010). A brief tutorial on Maxent. Lessons in Conservation, 3: 107-135.

Phillips, S.J., Dudík, M. \& Schapire, R.E. (2004). A maximum entropy approach to species distribution modeling. In Proceedings of the Twenty-First International Conference on Machine Learning, 655-662. ACM Press, Newyork.

Sarıkaya, O., Karaceylan, I.B. \& Şen, İ. (2018). Maximum Entropy Modeling (MaxEnt) of current and future distributions of Ips mannsfeldi (Wachtl, 1879) (Curculionidae: Scolytinae) in Turkey. Applied Ecology and Environmental Research, 16(3):25272535.

TÜIK, (2014). Türkiye İstatistik Kurumu, Bitkisel Üretim İstatistikleri.

Wei, B., Wang, R., Hou, K., Wang, X. \& Wu, W. (2018). Predicting the current and future cultivation regions of Carthamus tinctorius L. using MaxEnt model under climate change in China. Global Ecology and Conservation, 16 (2018) e00477.

West, A.M., Kumar, S., Wakie, T., Brown, C.S., Stohlgren, T.J., Laituri, M., Bromberg, J. (2015). Using high-resolution future climate scenarios to forecast Bromus tectorum invasion in Rocky Mountain National Park. PLoS ONE 10(2): e0117893.doi:10.1371/journal.pone.0117893.

WorldClim, (2019). WorldClim - Global Climate Data. www.worldclim.org, Erişim tarihi: 14.05.2019. 